In the group of patients treated with physical rehabilitation $(n=33)$, a significant improvement of the VAS of pain and of the physical mean score of SF36 was noted only on day 18 (Table 2). A significant improvement of the mental mean score of SF 36 was noted on day 18 and 6 months (Table 2).

Table 2. Tendencies of the clinical indexes after treatment by physical rehabilitation

\begin{tabular}{|c|c|c|c|c|c|}
\hline & $\begin{array}{c}\text { D0 } \\
(n=37)\end{array}$ & $\begin{array}{c}D 18 \\
(n=33)\end{array}$ & $\begin{array}{c}3 \text { months } \\
(n=28)\end{array}$ & $\begin{array}{c}6 \text { months } \\
(n=29)\end{array}$ & $\begin{array}{l}12 \text { months } \\
(\mathrm{n}=25)\end{array}$ \\
\hline $\begin{array}{l}\text { VAS } \pm S D \\
P\end{array}$ & $64 \pm 19,5$ & $\begin{array}{c}47,4 \pm 24,6 \\
0,002\end{array}$ & $\begin{array}{c}55,7 \pm 18,1 \\
0,091\end{array}$ & $\begin{array}{c}50,5 \pm 27,5 \\
0,057\end{array}$ & $\begin{array}{c}62,2 \pm 22,2 \\
0,567\end{array}$ \\
\hline $\begin{array}{l}\mathrm{ODI} \pm \mathrm{SD} \\
\mathrm{P}\end{array}$ & $34,3 \pm 12,3$ & $\begin{array}{c}31,1 \pm 17,3 \\
0,268\end{array}$ & $\begin{array}{c}31,9 \pm 15,6 \\
0,258\end{array}$ & $\begin{array}{c}30,3 \pm 18,8 \\
0,296\end{array}$ & $\begin{array}{c}31,1 \pm 12 \\
0,150\end{array}$ \\
\hline $\begin{array}{l}\text { SF } 36 \text { physical } \\
\text { mean score } \pm \text { SD }\end{array}$ & $38,1 \pm 16,1$ & $53,8 \pm 22$ & $42,6 \pm 16,4$ & $45,1 \pm 18,7$ & $42,6 \pm 16,2$ \\
\hline P & & 0,002 & 0,284 & 0,202 & 0,185 \\
\hline $\begin{array}{l}\text { SF36 mental } \\
\text { mean score } \pm \text { SD }\end{array}$ & $39,3 \pm 17,5$ & $61,6 \pm 23,5$ & $45,1 \pm 18,9$ & $49,6 \pm 24,6$ & $46,9 \pm 22,1$ \\
\hline $\mathbf{P}$ & & 0,000 & 0,130 & 0,033 & 0,09 \\
\hline $\begin{array}{l}\text { Schober test } \pm \text { SD } \\
\text { P }\end{array}$ & $3,2 \pm 1,4$ & $\begin{array}{c}3,5 \pm 1,3 \\
0,845\end{array}$ & $\begin{array}{c}3,4 \pm 1,4 \\
0,983\end{array}$ & $\begin{array}{c}2,7 \pm 1,2 \\
0,091\end{array}$ & $\begin{array}{c}2,9 \pm 1,3 \\
0,346\end{array}$ \\
\hline
\end{tabular}

VAS: visual analog scale; ODI: Oswestry Disability Index; SF36: short form 36

Comparison of the two types of tested treatments showed a certain number of statistically significant differences. The VAS and physical mean score of SF 36 at day 18 and mental mean score of SF-36 at 3 months were significantly lower on the thermal cure group, while schober test at 3 months was significantly lower in the physical rehabilitation group.

Conclusion: Our study suggests a superiority of thermal cure in relieving pain and improving quality of life at short term among patient with LBP and a comparable efficacy in improving lumbar spine function. However, the effectiveness of physical rehabilitation was greater on spine mobility.

Disclosure of Interests: None declared

DOI: 10.1136/annrheumdis-2020-eular.2212

\section{AB1261 DOUBLE-BLIND PLACEBO-CONTROLLED TRIAL OF PULSED ELECTROMAGNETIC FIELD THERAPY IN KNEE OSTEOARTHRITIS (PRELIMINARY RESULTS)}

D. Karateev ${ }^{1}$, A. Makevnina ${ }^{1}$, A. Tangieva ${ }^{1}$, E. Luchikhina ${ }^{1}$, H. Hamhoeva ${ }^{1}$. ${ }^{1}$ Moscow Regional Research and Clinical Institute ("MONIKI"), Rheumatology Department, Moscow, Russian Federation

Background: Pulsed electromagnetic field (PEMF) therapy is widely used in different areas of medicine. There are a lot of portable PEMF therapeutic devices on the market around the world. Nevertheless, the role of PEMF in treatment of rheumatic conditions is not clear. Current evidence is of low and very low quality. Objectives: To study efficacy and safety of PEMF therapy in primary and secondary osteoarthritis (OA) of the knee in controlled clinical trial.

Methods: This abstract presents the preliminary results of an ongoing double-blind placebo-controlled trial of PEMF portable therapeutic device "ALMAG+" (Certificate EN ISO 13485:2012+AC:2012 reg.-No 44221 117836, Yelatma Instrument-Making Enterprise, Russian Federation, Reg. Num.: 3007075140). The device is intended for physiotherapeutic treatment and rehabilitation with a low-frequency low-intensity PEMF in medical institutions, as well as at home after the recommendation of a doctor. Patients with primary and secondary (as a part of inflammatory rheumatic disease) OA of knee with Kellgren-Lawrence Grade I-III included in the study (in patients with inflammatory conditions disease activity should be minimal on stable drug therapy). Three courses of PEMF of 20 procedures for 1 year planned in active treatment group and placebo (inactive device) group of 35 patients each. Efficacy is evaluated by pain VAS, WOMAC, Lequesne index, and quality of life studied using SF-36, EuroQoL 5D tools. Instrumental control with knee ultrasound and MRI investigations will be performed. The study protocol was approved by local Ethical Committee.

Results: To date 23 patients ( 7 males, 16 females, age $54,6 \pm 11,2$ years, primary knee OA - 16 pts, RA- 6 pts, AS - 1 pt) completed $1^{\text {st }}$ course of PEMF. Table presents differences $(\Delta)$ in the main clinical parameters in active treatment and placebo device groups. No significant difference in ESR or CRP levels was found. No treatment-related adverse events has been reported.
Table. Differences $(\Delta)$ in the main clinical parameters after a $1^{\text {st }}$ course of PEMF.

\begin{tabular}{lccc}
\hline Parameter & $\begin{array}{c}\text { Active device } \\
(\mathbf{n}=\mathbf{1 1})\end{array}$ & $\begin{array}{c}\text { Placebo device } \\
(\mathbf{n}=\mathbf{1 2})\end{array}$ & $\mathbf{p}$ \\
\hline$\Delta$ VAS pain in movement & $15[0 ; 38,5]$ & $5[1,25 ; 10,5]$ & 0,053 \\
$\Delta$ VAS pain in rest & $10[0 ; 34]$ & $1[0 ; 2,75]$ & 0,043 \\
$\Delta$ WOMAC & $3[2 ; 10]$ & $2[0 ; 4,5]$ & 0,174 \\
$\Delta$ Lequesne index & $3[0 ; 4]$ & $1[0,25 ; 2,5]$ & 0,258
\end{tabular}

Conclusion: In this preliminary analysis pulsed electromagnetic field (PEMF) therapy showed significant impact on pain in rest in knee OA after one course of procedures.

References: Negm A, Lorbergs A, Macintyre NJ. Efficacy of low frequency pulsed subsensory threshold electrical stimulation vs placebo on pain and physical function in people with knee osteoarthritis: systematic review with meta-analysis Osteoarthritis Cartilage. 2013 Sep;21(9):1281-9. doi: 10.1016/j.joca.2013.06.015 Disclosure of Interests: Dmitry Karateev Consultant of: Abbvie, Pfizer, Biocad Sanofi, Novartis, Lilly, Speakers bureau: Abbvie, Roche, Pfizer, Biocad, MSD, Sanofi, Johnson \& Johnson, Glaxo, UCB, Celgene, Novartis, Lilly, Bayer, Alexandra Makevnina Speakers bureau: Sanofi, Aminat Tangieva: None declared, Elena Luchikhina Consultant of: Abbvie, Biocad, Sanofi, Celgene, Speakers bureau: Abbvie, Roche, Pfizer, Biocad, MSD, Sanofi, Johnson \& Johnson, Glaxo, UCB Celgene, Novartis, Hava Hamhoeva: None declared DOI: 10.1136/annrheumdis-2020-eular.6396

\section{AB1262 EFFECTS OF TAI CHI EXERCISE ON PAIN, FUNCTIONAL STATUS AND QUALITY OF LIFE IN PEOPLE WITH OSTEOARTHRITIS AND INFLAMMATORY ARTHRITIS}

N. Kalebota ${ }^{1}$, M. Milošević ${ }^{2}$, N. Laktašić Žeriavić ${ }^{1}$, A. Andreićc ${ }^{3}$, B. Končar ${ }^{4}$ M. Vedriš ${ }^{4}$, P. Turković ${ }^{4}$, N. Žura ${ }^{1}$, K. Kovač Durmiš ${ }^{1}$, I. Žagar ${ }^{1}$, P. Perić ${ }^{1}$. ${ }^{1}$ Clinical Hospital Centre Zagreb, University Department for Rheumatology and Rehabilitation, Zagreb, Croatia; ${ }^{2}$ University of Zagreb, School of Medicine, Andrija Štampar School of Public Health, Zagreb, Croatia; ${ }^{3}$ Patient Advocacy Association, Zagreb, Croatia; ${ }^{4}$ Croatian Wushu Federation, Zagreb, Croatia

Background: Tai Chi as a type of physical activity (PA) is included in recommendations for PA in people with inflammatory arthritis $(I A)$ and osteoarthritis $(O A)$. Objectives: The aim of this study was to evaluate the effect of Tai Chi exercise program on pain, functional status and quality of life in people with OA and IA Methods: A study co-funded by the Erasmus + European Union Program for Sporting Activities called \#WushuElixir was conducted in Croatia, Slovenia, Belgium and Spain. We present the results of the research conducted in Croatia from October 2018 to April 2019. A total of 44 participants (Pts) entered the Tai Chi exercise program. Majority of Pts were female with OA (Table 1). Tai Ch exercise program was performed for 60 minutes, twice a week, with a total of 50 training sessions. In data analysis where included only those Pts who completed at least $36 \%$ of exercise program, a total of $28(63.6 \%)$ Pts, out of which 24 $(85.7 \%)$ completed at least $70 \%$ of exercise program. An average attendance was $39(78 \%)$ sessions. Outcome measures were: pain (VAS scale), stability and balance (Functional reach test; FRT), chest mobility (breathing index), spinal mobility (cervical and thoracic sagittal indices and Schober's test), muscle strength (Wall sit test), physical function (Lequesne Index of severity for OA of the hip, and Stanford Health Assessment Questionnaire (HAQ) 20-Item for IA) and quality of life (15DC) The health-related quality of life instrument; 15D QL). For statistical analysis t-test for paired samples was used with statistical significance set on $\mathrm{P}<0.05$

Table 1. Descriptive statistics of participants

\begin{tabular}{lccc}
\hline & & N & $\%$ \\
\hline Gender & Male & 4 & $14.3 \%$ \\
Age groups & Female & 24 & $85.7 \%$ \\
& $\leq 45$ years & 3 & $10.7 \%$ \\
& $46-60$ years & 9 & $32.1 \%$ \\
Diagnosis & 61-70 years & 11 & $39.3 \%$ \\
& $\geq 71$ years & 5 & $17.9 \%$ \\
& Osteoarthritis of the spine, hip and knee & 19 & $67.9 \%$ \\
& Inflammatory arthritis & 5 & $17.9 \%$ \\
& Other & 4 & $14.3 \%$ \\
\hline
\end{tabular}

Results: There was significant improvement in breathing index $(P<0.001)$ sagittal mobility of cervical $(P<0,001)$ and thoracic spine $(P=0.007)$, Schober's 